\title{
Wheat and its Importance of High Quality Protein that Effects the Human Health
}

\author{
Mamta Rathore ${ }^{1 *}$, Pragya Mishra ${ }^{2}$, Suman Devi ${ }^{3}$, Pooja Singh ${ }^{2}$, Khalil Khan ${ }^{4}$, H. G. Prakash ${ }^{5}$ \\ ${ }^{1}$ Project Fellow, Department of Agricultural Biochemistry, C. S. Azad University of Agriculture \& Technology, \\ Kanpur, India \\ ${ }^{2}$ Department of Food and Nutrition, C. S. Azad University of Agriculture \&Technology, Kanpur, India \\ ${ }^{3}$ Department of Food Technology, C. S. Azad University of Agriculture \&Technology, Kanpur, India \\ ${ }^{4}$ Department of Soil Science, C. S. Azad University of Agriculture \& Technology, Kanpur, India \\ ${ }^{5}$ Directorate of Research, C. S. Azad University of Agriculture \&Technology, Kanpur, India
}

\begin{abstract}
*Address for Correspondence: Dr. Mamta Rathore, Project Fellow, Department of Agricultural Biochemistry, Chandra Shekhar Azad University of Agriculture \& Technology, Kanpur, India
\end{abstract}

E-mail: mamtacsa@gmail.com; Fax Number: 91512-2533808

Received: 08 Jan 2020/ Revised: 24 Mar 2020/ Accepted: 25 May 2020

\begin{abstract}
Background- Mostly Wheat is a highly cultivated crop in the world. On the comparison of consumption, the two most important crop is wheat, rice and maize, which is used for the human diet. It is used for bread, cakes, pasta are prepared by wheat flour the fermented preparation for alcohol, beer, vodka and biofuels. Cornhusk separated by wheat flour, which is known as bran.

Methods- NIRS-2500 is a recent technology to apply the evaluation of grain properties such as their physical and biochemical properties.

Results- According to the our results, evaluation of wheat variety the protein , moisture, carbohydrate, ash, fiber, ADF, NDF and vitamin content were ranged from $15.28 \%$ to $15.57 \%, 15.28 \mathrm{~K}-402, \mathrm{~K}-9107$ to $15.57 \%, \mathrm{~K}-9644, \mathrm{~K}-4026.41 \%$ to $6.61 \%$, K-1317, K$96443.68 \%$ to $3.72 \%$, K-402, K-307, K-607 4.10\% to $4.12 \%, \mathrm{~K}-307, \mathrm{~K}-9162$,7.24\% to $7.54 \% \mathrm{~K}-402, \mathrm{~K}-9644,17.66 \%$ to $17.90 \%$, K402, K-9644 and $27.01 \%$ to $27.79 \% \mathrm{~K}-402, \mathrm{~K}-1317$, K-9644 and K-1317.

Conclusion- The modern time quantity-wise natural fiber was used in flax, hemp, jute, straw, wood, rice husk, wheat, barley oats, rye and cane etc are used in plastic preparation. The properties of thermoplastic such as lightweight, strength and stiffness to used in thermoplastics. The wheat varieties of the best quality parameter were K-402, K-9644, K-607, K-9551, K-9644, and K-1317.
\end{abstract}

Key-words: Biofuels, Biocomposite, Cornhusk, Domestication, Human Diet, Natural Fiber, Wheat flour

\section{INTRODUCTION}

Wheat is an energy provider so that it is mostly nutrientrich, which contains protein, fiber and lipids, vitamins, minerals and phytochemicals are the main component of healthy diet. Wheat products are Cereals and bread were the main source of energy for all age groups, contributing $31 \%$ for adults, and of non-starch polysaccharides with bread alone contributing about a fifth of the average daily intake.

\section{How to cite this article}

Rathore M, Mishra P, Devi S, Singh P, Khan K, Prakash HG. Wheat and its Importance of High Quality Protein that Effects the Human Health. SSR Inst. Int. J. Life Sci., 2020; 6(4): 2617-2622.

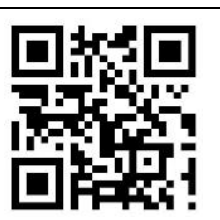

In addition cereals, including wheat, contribute significantly to the daily intake of protein, B vitamins, and iron. These high contributions of wheat to essential nutrients in the UK, a comparatively prosperous country with a varied diet, underline its importance to nutrition globally ${ }^{[1]}$.

Limited data are available for less developed countries but some comments can be made. In India, the diets of the rural poor are based predominantly on cereals, which provide $80 \%$ of energy and other nutrients except for vitamins $A$ and $C$. Cereals, therefore, require supplementation with other food groups such as pulses, vegetables, fruits, or animal products to make the diet more balanced and adequate, particularly to vitamin A, iron, and riboflavin. However, most suggested that the diets of the poor can also be improved to reduce the 
incidence of major nutrient deficiencies such as vitamin A deficiency and iron deficiency anemia by replacing a cereal diet with mixed cereals, including millets ${ }^{[2,3]}$.

Wheat grain composition about diet and health- To focus on components of direct relevance to human nutrition and health and compare data for two fractions, wholegrain and white flour ${ }^{[2,3]}$. We will also consider data on the locations of components within the different tissues of the grain, as this is relevant to their recovery in milling fractions, and briefly discuss the roles of grain components in diet and health. Some grain components, such as protein and B vitamins, have established roles in the growth and health of humans and these roles will not be discussed in detail here ${ }^{[3,4]}$.

Protein content grain protein content is determined by genetic and environmental factors, notably the availability of nitrogen fertilization. The protein content of 12,600 lines in the USDA world wheat collection has been reported to range from $7 \%$ to $22 \%$ of the dry weight but generally varies from about $10-15 \%$ of the dry weight for wheat cultivars grown under field conditions ${ }^{[5-6]}$. The separate cultivars are bred for livestock and food; these may differ in protein content by about $2 \%$ protein when grown under the same conditions.

Protein nutritional quality is determined by the proportions of essential amino acids, as these cannot be synthesized by animals and hence must be provided in the diet. If only one essential amino acid is limiting, the others will be broken down and excreted resulting in restricted growth in humans and loss of nitrogen present in the diet. Ten amino acids are strictly essential lysine, isoleucine, leucine, phenylalanine, tyrosine, threonine, tryptophan, valine, histidine, and methionine [7,8]. However, cysteine is often also included as it can only be synthesized from methionine, with combined proportions of cysteine and methionine often being presented. The requirements for essential amino acids are lower for adults where amino acids are required only for maintenance, than for children, where they are also required for growth. Lipids are present only in a small extent in cereals but they have a significant effect on the quality and the texture of foods because of their ability to associate with proteins due to their amphipathic nature and with starch, forming inclusion complexes. In wheat, the maturing seed synthesizes fatty acids at different rates. The biosynthesis of lipids depends upon acetyl coenzyme A. This important compound is involved in the synthesis of the acyl lipids such as glycerides, phospholipids, waxes, sphingosine lipids as well as the isoprenoid series. Malonyl-CoA is also utilized, together with NADPH, and further dehydration and condensation reactions occur to produce palmitic acid (C16:0), which can then be extended to stearic acid by another reaction. Synthesis of linoleic acid occurs in higher plants by two separate pathways in the presence of microsomal enzymes. Isopentenyl pyrophosphate is formed from mevalonic acid which in turn is synthesized from acetyl CoA ${ }^{[9,10]}$. It can form $b$-squalene and, from this compound, the characteristic steroid structures, of which cholesterol is a member, are produced, although in very small amounts. The germ has the highest amount of lipids (11\%), but significant amounts are also associated with the bran and the starch and proteins of the endosperm. Complex polar lipids extracted by WSB (1butanol saturated with water) account for about half the total lipids in the endosperm compared with about $23 \%$ in the bran and $17 \%$ in the germ, but the latter two contain more triglicerides. The bound lipids are mostly phosphatidyl choline, phosphatidyl ethanolamine and phosphatidyl serine, as well as Iysophosphatidyl derivates, where there is one free hydroxyl group on the glycerol moiety ${ }^{[11,12]}$. The principal sterols were identified as b-sitosterol, campesterol and C28 and C29 saturated sterols. Numerous studies have been carried out showing a high level of linoleate (C18:2) in both the total lipid and the triglycerides from the three fractions with lower amounts of palmitate (C16:0) and oleate (C18:1) ${ }^{[13,14]}$.

\section{MATERIALS AND METHODS}

Sample preparation- To prepare the wheat samples from the crops were picked and threshed to remove the peels. We also noticed the physical property of wheat which varies from light brown color, soft and smooth \& regular in size of grain to dark brown in color to soft rough in texture.

The seed samples were kept at a temperature of $25^{\circ} \mathrm{C}$ and relative humidity of approximately $85 \%$ in an airconditioned laboratory overnight to attain temperature equilibrium of the seeds before measurement. The 12 samples of wheat seeds were analyzed for their proximate composition. All the work on this investigation was done in the laboratories of NIRS in the directorate of research, C. S. Azad University of Agriculture and 
Technology, Kanpur (UP). The grain seed of wheat was collected from the legume section of Azad university of Agriculture \& Technology, Kanpur. After cleaning and grading the seed samples were determined using NIRS2500. For analysis, we should use three replications for each sample and used the average value for the spectrum calibration. We take $130 \mathrm{gm}$ samples to analyze the sample it works from $400-2500 \mathrm{~nm}$ wavelength.

NIRS-2500 (Near Infrared) analysis- It is an instrument through, which Near Infrared (NIR) analysis a spectroscopic technique that makes use of the naturally occurring electromagnetic spectrum. This works in the region of the spectrum defined by wavelengths between $700 \mathrm{~nm}$ and $2500 \mathrm{~nm}$. It is suited for the quantitative determination of the major constituents in most types of food and agricultural products.

Near Infrared light is directed onto a sample principle working instrument. The light is modified according to the composition of the sample and this modified light is detected (see transmission and reflectance below) ${ }^{[15,16]}$. The spectral modifications are converted to information regarding the composition of the sample of the crop. These conversion algorithms are called "calibrations" Infrared spectrum was got by using infrared light, which passes through the sample by following the transmission. The lights were reflected by the sample and follow the absorption properties, which can be extracted from the reflectance. This spectroscopy can be analyzed the sample by transmittance is good for measuring cheese to obtain a representative measurement throughout the sample. For homogenous samples such as milk powder, the reflectance is ideal.

The research was conducted in the Laboratory with the help of NIRS-2500 instruments. According to the Table 1, there are eleven variety of wheat was evaluated among them there are eight characteristics, which was evaluated such as protein, moisture, carbohydrate, ash, fiber, ADF,NDF and vitamin-A. The mean of Protein is 16.65, moisture has 12.23, carbohydrate 7.01, ash 3.39, fiber 4.11, ADF 7.45, NDF 16.29 and Vitamin A has 27.49 mean. The values of the most characteristics were significantly ${ }^{[17-19]}$.

\section{RESULTS}

The result in Table 1 shows the presence of protein, moisture, carbohydrate, ash, fiber, ADF, NDF and Vitamin A. In wheat seed, we evaluated thirteen varieties namely as K-9423, K-9107, K-1006, K-9351, K-9242, K9006, K-1317, K-9644, K-1317, K-607, K-9162, K-307 and $\mathrm{K}-402$. Although wheat is known for controlling obesity, this benefit is far more active in women than in men. Improves body Metabolism. When your body's metabolism is not functioning at an optimal level, it can lead to a variety and reduced the chronic Inflammation. Chronic inflammation refers to any inflammation that has lasted for a few months.

Table 1: Physical characteristics analyzed by NIRS-2500

\begin{tabular}{|c|c|c|c|c|c|c|c|c|c|}
\hline S.No. & $\begin{array}{l}\text { Wheat } \\
\text { Variety }\end{array}$ & $\begin{array}{c}\text { Protein } \\
(\%)\end{array}$ & $\begin{array}{c}\text { Moisture } \\
(\%)\end{array}$ & $\begin{array}{c}\text { Carbohydrate } \\
(\%)\end{array}$ & $\begin{array}{l}\text { Ash } \\
(\%)\end{array}$ & Fiber (\%) & ADF (\%) & NDF (\%) & $\begin{array}{c}\text { Vitamin A } \\
(\%)\end{array}$ \\
\hline 1. & K-9423 & 15.34 & 13.25 & 6.53 & 3.71 & 4.11 & 7.47 & 17.76 & 27.67 \\
\hline 2. & K-9107 & 15.28 & 13.34 & 6.43 & 3.70 & 4.10 & 7.52 & 17.73 & 27.79 \\
\hline 3. & K-1006 & 15.31 & 13.31 & 6.47 & 3.71 & 4.10 & 7.52 & 17.75 & 27.73 \\
\hline 4. & K-9351 & 15.49 & 13.42 & 6.47 & 3.71 & 4.12 & 7.39 & 17.90 & 27.04 \\
\hline 5. & K-9242 & 15.37 & 13.28 & 6.55 & 3.70 & 4.11 & 7.44 & 17.80 & 27.41 \\
\hline 6. & K-9006 & 15.29 & 13.27 & 6.46 & 3.71 & 4.11 & 7.50 & 17.74 & 28.16 \\
\hline 7. & K-1317 & 15.33 & 13.41 & 6.41 & 3.70 & 4.11 & 7.49 & 17.75 & 27.79 \\
\hline 8. & K-9644 & 15.35 & 13.20 & 6.61 & 3.72 & 4.12 & 7.54 & 17.90 & 27.41 \\
\hline 9. & K-607 & 15.42 & 13.25 & 6.38 & 3.71 & 4.11 & 7.45 & 17.88 & 27.98 \\
\hline
\end{tabular}




$\begin{array}{lrrrrrrrrr}\text { 10. } & \text { K-9162 } & 15.50 & 13.43 & 6.61 & 3.72 & 4.11 & 7.36 & 17.73 & 27.36 \\ \text { 11. } & \text { K-307 } & 15.30 & 13.38 & 6.43 & 3.72 & 4.12 & 7.53 & 17.74 & 27.62 \\ \text { 12. } & \text { K-402 } & 15.57 & 13.49 & 6.42 & 3.68 & 4.11 & 7.24 & 17.66 & 27.01 \\ & \text { Mean } & 16.65 & 12.23 & 7.01 & 3.39 & 4.11 & 7.45 & 16.29 & 27.49\end{array}$

In Table 2, we have evaluated the physical parameter of the wheat seed. It is very important such as color, size and texture of the different variety of seed. The size which ranges from regular to irregular color varies from light brown to dark brown. The texture varies from soft and smooth to rough and smooth. Among them K-1006, K-9242, K-9644and K-307 were dark brown in color and soft and rough in the parameter.

Table 2: Physical property of the wheat variety

\begin{tabular}{|c|c|c|c|c|}
\hline S. No. & Wheat variety & Size & Color & Texture \\
\hline 1. & K-9423 & regular & Light brown & Soft and Smooth \\
\hline 2. & K-9107 & regular & Light brown & Soft and Smooth \\
\hline 3. & K-1006 & regular & Dark brown & Soft and Rough \\
\hline 4. & K-9351 & regular & Light brown & Soft and Smooth \\
\hline 5. & K-9242 & regular & Dark brown & Soft and Rough \\
\hline 6. & K-9006 & regular & Light brown & Soft and Smooth \\
\hline 7. & K-1317 & regular & Light brown & Soft and Smooth \\
\hline 8. & K-9644 & regular & Dark brown & Soft and Rough \\
\hline 9. & $K-607$ & regular & Light brown & Soft and Smooth \\
\hline 10. & K-9162 & regular & Light brown & Soft and Smooth \\
\hline 11. & $K-307$ & regular & Dark brown & Soft and Rough \\
\hline 12. & $K-402$ & regular & Light brown & Soft and Smooth \\
\hline
\end{tabular}

\section{DISCUSSION}

It was found that among these variety protein content and moisture was rich in K-402, K-9162 the carbohydrate content was higher in K-9242, K-1006 and K-9351. The ash content was higher in K-9644 and fiber was rich in K9162, K-9644, The ADF and NDF K-307, K-9644, K-607, K9242. The vitamin content was rich in K-K-1317, K-9107, and K-607.

According to Table 2, the regular, irregular rough and smooth wheat are studied boosts income and adds soil protection. One of the main advantages to wheat it is an ideal fall cover crop that you can later decide to harvest as a cash crop.

It is an excellent double crop that leaves a lot of residues to keep the topsoil from washing away. Disease and pests are also rarely a problem ${ }^{[20,21]}$.

The protein quality, which is obtained from animalsource food proteins, is not equal even though they are all highly digestible in the human gastrointestinal tract. The wheat whey is often considered to be better than casein for muscle builders consuming protein powder after exercise. 
The protein has a higher content of arginine, leucine, lysine and sulfur-containing AA (methionine and cysteine) than casein. Second, individual $A A$ is released more rapidly from whey protein in the small intestine to support muscle protein synthesis immediately after exercise ${ }^{[22-24]}$. Thus, consumption of whey protein stimulated postprandial muscle protein accretion more effectively than casein or casein hydrolyzed in elderly men ${ }^{[24,25]}$. In addition, when supplemental whey protein ( 0.15 g protein per kg BW per day) was consumed for 24 weeks by postmenopausal women immediately after weight training, skeletal-muscle strength was consistently improved by $9 \%$. In contrast, inconsistent results (including no change) in muscle strength were reported for elderly men who consumed a casein supplement (20 g per session; 3 sessions per week) immediately before and after resistance training. However, it is unknown whether such a pattern of casein supplementation is sufficient to sustain elevated levels of AA in the plasma to stimulate muscle protein synthesis.

\section{CONCLUSIONS}

Findings from wheat studies have been variable. Among thirteen wheat varieties protein, moisture rich varieties are K-402, carbohydrate-rich varieties are K-9644, ash content-rich in K-307, K-607, fiber was higher in K-9162, K-9351, ADF-rich in K-9644, K 1006, K-9107, and NDF was superior in K-9644, K-607, K-9242 and vitamin A rich in $\mathrm{K}$ 1317, K-9644, K1317. So these are nutrition rich varieties which effect the positive manner in human health.

The future aspects of the wheat crop are that during the present time the $R \& D$ sector was suffered from climatic changes such as drought, high temperature etc so that wheat breeder and researcher want to design such type of research framework which provides us efficiently data and authentic results, which improve the human health. We get energy and other valuable things from the food that we eat. Among the top food items, people always prefer taking the food that has the right amount of nutrients for a perfect diet. Fruits and vegetables are important things in food groups.

\section{ACKNOWLEDGMENTS}

This research was conducted at Directorate of research, the Chandra Shekhar Azad University of Agriculture \&Technology, Kanpur under NAHEP Center for advanced agriculture Science \& Technology on nutritional crops sponsored by ICAR, New Delhi. The financial assistance is duly acknowledged and thanks for Director Research of the University for providing me with the research support.

\section{CONTRIBUTION OF AUTHORS}

Research concept- Mamta Rathore

Research design- Mamta Rathore

Supervision- H. G. Prakash

Materials- Khalil Khan

Data collection- Pragya Mishra

Data analysis and Interpretation- Pooja Singh

Literature search- Suman Devi

Writing article- Mamta Rathore, Pooja Singh

Critical review- H. G. Prakash

Article editing-Khalil Khan

Final approval- H. G. Prakash

\section{REFERENCES}

[1] Morell MK, Li Z, Regina A, Rahman S, d'Hulst C, et al. Control of primary metabolism in plants. Annual Plant Reviews, Volume 22, 2006; 258-89.

[2] Murphy DJ. Bacillus thuringiensis Insecticidal Cry1ab Toxin Does Not Affect the Membrane Integrity of the Mammalian Intestinal Epithelial Cells: An in Vitro Study. In Vitro Cell Dev Biol Anim., 2006; (42): 89-99.

[3] Ortiz-Monasterio JI, Palacios-Rojas N, Meng E, Pixley $R$, Trethowan $R$, et al. Enhancing the mineral \& vitamin content of wheat and maize through plant breeding. J Cereal Sci., 2007; 46: 293-307.

[4] Liu QQ. Method to produce desired proteins in plants. Ph D. Dissertation, Yangzhou University and The Chinese University of Hong Kong, 2002; 1053-59.

[5] Lopez HW, Krepine V, Guy C, Messager A, Demigne $C$, et al. Prolonged fermentation of whole wheat sourdough reduce phytate level \&increase soluble. J Agric Food, 2001; 49(5): 2657-62.

[6] Cornell H, Cauvain SP. Bread Making Improving quality. Wood head Publishing Cambridge, 2003; 85709-0607.

[7] Dalmo RA, Bogwald J. Proteomic analysis of muscle tissue from rainbow trout fed dietary beta-glucan. Fish Shellfish Immunol., 2008; 25: 384-96.

[8] Ehrenbergerova J, Brezinova BN, Psota V, Hrstkova P, Cerkal $\mathrm{R}$, et al. Changes caused by genotype and environmental conditions in beta glucan content of spring barley for dietetically beneficial human nutrition. Plant Foods Hum Nutr., 2008; 63: 141-45. 
[9] Cakmak I, Enrichment of cereal grains with Zn, Agronomic or Genetic biofortification. Plant Soil, 2008; 302: 1-17.

[10]Englyst HN, Kingman SM, Hudson GJ, Cumming JH. Rapidly available glucose in foods: an in vitro measurement that reflects the glycemic response. Br J Nutr., 1996; 75: 749-55.

[11]Ali MA. Nawab NN, Rasool G, Saleen M. Estimates of variation correlations for quatitative traits in Cicer arietimum L. J Agri Societal Sci., 2008; 4(4): 177-79.

[12]Rahman MM, Hossain ABS, Saba NK, Malaku PK. Selection of morpho-physiological traits for heat tolerance in wheat. Bangladesh J Sci Ind Res., 2017; 32 (2): 161-65.

[13]Slafer GA, Satorre EH. An introduction of wheat yield. In Eds Saltorre H \& GA Slafer. Wheat Eco \& Physio of yield determination. 1999; pp. 3-12.

[14]Saleem S, Kashif M, Ashraf MY, Saleen U. Assessment of genetic effects of some physiological parameters in spring wheat under water stress. Pak J Bot., 2017; 49(6): 2133-37.

[15]Randhwa MA, Anjum FM, Butt MS. Physico chemical \& milling properties of new spring wheat grown in Punjab and Sind for the production of pizza. Int J Agric Biol., 2002; 4: 482-84.

[16]Abou E, Salwa MF. Carboxylic acids as biomarkers of biomphalaria alexandrina snails Infected with Schistosoma mansonikor. J Parasites, 2010, 48 (2): 127-32.

[17]Hussain SS, Qamar R. Wheat genomics challenges and alternative strategies. Proc Pak Acad Sci., 2007; 44: 305-06.
[18]World Health Organization. Reports of the scientific working group meeting on schistos omiasis, 2005; 123.

[19]Aune D, Keum N, Giovannucci E, et al. Whole grain consumption and risk of cardiovascular disease, cancer, and all cause and cause specific mortality: systematic review and dose-response meta-analysis of prospective studies. BMJ, 2016; 353: i2716.

[20]de Jong N, Hoender-Vangers CT, Bleeker JK, et al. The opinion of Dutch dietitians about functional foods. J Hum Nutr Diet, 2004; 17: 55-62.

[21]5. Hauner H, Bechthold A, Boeing $\mathrm{H}$, et al. Evidencebased guideline of the German Nutrition Society: carbohydrate intake and prevention of nutritionrelated diseases. Ann Nutr Metab, 2012; 60(1S): 158.

[22] Ge Y, Sun A, Ni Y. Some nutritional and functional properties of defatted wheat germ protein. J Agric Food Chem. 2000; 48: 6215-18.

[23]Rehman S, Nazir Y, Hussain S. Huma N. Study on the evaluation of wheat varieties of sindth province for the production of ring doughnuts. JAPS, 2001; 3 : 135-38.

[24]Cara L, Borel P, Armand $M$, et al. Plasma lipid lowering effects of wheat germ in hyper cholesterolemic subjects. Plant Foods Hum Nutr., 1991; 41: 135-50.

[25]European Food Safety Authority. Guidance on the scientific requirements for health claims related to antioxidants, oxidative damage and cardiovascular health. EFSA J., 2011; 9(12): 2474. 